\title{
Fetal blood sampling and gas exchange
}

\author{
J. F. PEARSON
}

From the Department of Obstetrics, University Hospital of Wales, Cardiff

Asphyxia remains a common cause of intrapartum fetal death. In Cardiff in the four-year period 1968-1972, 192 infants died in labour. Whilst prematurity and lethal congenital abnormalities accounted for 36 per cent of these, the remaining deaths were due to asphyxia: abruptio placentae (19 per cent); cord prolapse (11 per cent); infants 'at risk' ( 22 per cent) and infants not 'at risk' (12 per cent).

Many of these deaths might have been avoided by the routine use of continuous fetal heart rate monitoring had it been available. However, abnormalities of the fetal heart rate pattern are only suggestive of fetal asphyxia, and it is becoming generally accepted that the $\mathrm{pH}$ of a fetal scalp blood sample offers the most reliable indicator of fetal asphyxia in present-day use.

\section{The Rationale of Fetal Blood Sampling}

The fetal monkey, when totally asphyxiated, decreases its blood $\mathrm{pH}$ at about $0 \cdot 1 \mathrm{pH}$ unit per minute and its base excess at 4.0 m-equiv/l per minute, while its $\mathrm{PCO}_{2}$ increases at $13 \mathrm{mmHg}$ per minute (Adamsons et al, 1964). The fall in $\mathrm{pH}$ is due to carbon dioxide and lactate accumulation. Total fetal asphyxia is rarely encountered in practice and is only likely to occur with acute retroplacental haemorrhage or cord occlusion following cord prolapse.

Partial oxygen deprivation in the fetus results in the following sequence of events. Hepatic glycogen is mobilized and broken down anaerobically along the glycolytic pathway (Embden-Meyerhof pathway), releasing energy and producing pyruvate. Normally, pyruvate is fed into the Kreb's tricarboxylic acid cycle where it is further metabolized aerobically. Under conditions of oxygen deprivation pyruvate production increases and, in order to maintain a rapid rate of glycolysis, it is removed almost as fast as it is formed, by conversion to lactate, which then accumulates in the fetal tissues causing a metabolic acidosis and a fall in blood pH. During hypoxia the fetal $\mathrm{PCO}_{2}$ rises, increasing the level of $\mathrm{H}_{2} \mathrm{CO}_{3}$ in the fetal blood, and giving rise to a respiratory acidosis and a fall in blood $\mathrm{pH}$. The combination of hypoxia, hypercarbia and metabolic acidosis constitutes asphyxia. At any given level of oxygen depletion, the survival time of the hypoxic fetus will depend primarily on its glycogen reserve. Thus, the well nourished fetus can be expected to withstand a standard hypoxic insult better than the growthretarded fetus.

The fetus is unable to compensate for acute metabolic acidosis by increasing pulmonary $\mathrm{CO}_{2}$ excretion and combats acidosis by utilizing its buffer systems, including haemoglobin. If a pure metabolic acidosis is produced in fetal blood, the oxygen dissociation curve shifts to the right (Bohr effect) causing a change in oxygen affinity, such that for a given $\mathrm{PO}_{2}$ the oxygen saturation falls. This has the dual beneficial effect of increasing the quantity of reduced haemoglobin, which is then utilized as buffer, and releasing oxygen from the red cells, which then becomes available to the tissues (Hellegers et al, 1969). Because of its high concentration of haemoglobin, the buffering of blood in the normal fetus is considerable, thus the fetus with erythroblastosis is at a great disadvantage,

The maintenance of blood pH is of vital importance in the maintenance of efficient glycolysis, for as $\mathrm{pH}$ falls, the rate of glycolysis is progressively inhibited. In the lamb it ceases altogether at pH 6.7 (Dawes et al, 1963). It thus seems likely that when the buffer systems have become saturated with hydrogen ions the $\mathrm{pH}$ falls abruptly to levels incompatible with life.

\section{Fetal Blood Sampling}

The introduction of fetal blood sampling by Saling (1963), whereby arterialized capillary blood could be obtained from the fetus during labour, revolutionized the diagnosis of intrapartum fetal asphyxia. Saling (1966) showed that a scalp blood pH of $<7 \cdot 20$ was associated with poor clinical condition of the infant and he designated values below $\mathbf{7 . 2 0}$ as 'acidosis'; he also suggested that a fetal scalp blood $\mathrm{pH}$ of between 7.20 and 7.25 was indicative of early fetal deterioration and he designated values within this range as 'preacidosis'.

The sample of blood, if properly taken, should 
conform to the standards set for arterialized capillary blood by the New York Academy of Science ad hoc committee on acid-base terminology (1966) and, as such, should reflect the acid-base and blood gas status of the fetus as a whole. The validity of scalp samples has been established in different ways. Scalp blood taken just before birth and blood taken from the umbilical vessels at the moment of delivery have shown good correlation in terms of blood gas and acid-base variables (Saling 1966; Beard and Morris, 1965; Kubli, 1968). Gare et al (1967) compared blood taken from the hyperaemic scalp of the exteriorized fetal lamb with fetal arterial blood, and Adamsons et al (1968) performed a similar study using the rhesus monkey. Both groups of workers confirmed the validity of fetal blood sampling.

\section{The Technique of Fetal Blood Sampling}

The parturient patient is placed in the lithotomy position but is tilted to one side, with a rubber wedge or pillow placed under a buttock to prevent aortocaval compression. Alternatively, if the head is deeply engaged within the pelvis, the sample can easily be obtained by placing the patient in Sims' position.

The external genitalia are swabbed with 1 per cent aqueous Savlon solution and the vulva is isolated using sterile drapes. Following a vaginal examination to check cervical dilatation, an endoscope and obturator of suitable size are passed into the posterior vaginal fornix. The obturator is removed, a fibreoptic light is attached and, under direct vision, the endoscope is manoeuvred so as to rest evenly against the fetal scalp.

This modification of the technique usually described (Beard, 1970) causes much less discomfort to the patient and is particularly useful when the cervix is only slightly dilated. It is important to angle the endoscope correctly, placing its tip evenly against the scalp, since otherwise liquor may leak around the edges, thus contaminating the field. Therefore, as a general rule, it is advisable that the higher the fetal head the lower should be the operator. Many operators kneel on a small cushion placed on the floor; alternatively a low stool can be provided. The angle of the endoscope within the pelvic axis should be the same as that which would be subtended by the shanks of Keilland's forceps were they to be applied at that level. The alternative manoeuvre of tilting the patient head down makes access easier for the operator but may disimpact the presenting part and is, therefore, not recommended.

If the membranes are intact, they are ruptured and if the head is not engaged, it is steadied by an assistant. If this latter practice is not followed, the fetus, being stimulated into activity by the procedure, will move about during the operation and spoil the field.

After the scalp has been dried carefully with a dental swab on a holder, the operator sprays it with ethyl chloride under direct vision. It is of the greatest importance that a hyperaemic flush develop. Should the ethyl chloride spray fail to cause hyperaemia, the scalp is rubbed, perhaps several times, with the dental swab until a good hyperaemic flush develops. Silicone grease is then smoothed thinly over the area. It is good practice at this point, if the scalp is hairy, to make a parting in the hair with the butt end of the scalp blade holder, otherwise the capillary action of the hair will cause the blood to run along the hairs and not along the collecting tube.

Two stab incisions are made in the scalp at about 12 o'clock using a sharp, plastic-mounted $2 \mathrm{~mm}$ knife, which is then discarded. The optimal time for making the incisions is just before the onset of a uterine contraction. The globule of blood which forms is collected into a 12-inch long preheparinized capillary tube. The ideal sample consists of one full tube of blood $(0.2 \mathrm{ml})$ without air bubbles. An assistant, using a magnet, mixes the specimen with heparin by running a short steel rod up and down the lumen of the tube.

The blood samples are usually analysed using micro-Astrup equipment, which should be near to hand, and accurately calibrated with precision buffer before the fetal blood sample is taken. Modern equipment, such as the Radiometer BMS 3, mk 2, is capable of measuring $\mathrm{pH}, \mathrm{PCO}_{2}, \mathrm{PO}_{2}$, and base excess, in duplicate, on less than $0.2 \mathrm{ml}$ of scalp blood. More blood for a full acid-base analysis is required in older machines, such as the Radiometer AME 1 and BMS 2, mk 2, because measurement of $\mathrm{PCO}_{2}$ and base excess requires equilibration by tonometry of the fetal blood with two $\mathrm{CO}_{2} / \mathrm{O}_{2}$ gas mixtures.

\section{Fetal Acid-base Balance}

\section{NORMAL VALUES}

There is a lack of agreement among different workers on the normal range of fetal scalp blood acid-base values. The range of values published is wide and may reflect differences in technique, short-term variability in the composition of scalp blood or, as Jacobson (1970) remarked, 'the degree of acquaintance with fetal scalp sampling'. Lumley et al (1971) analysed acid-base values from 600 mainly abnormal patients and calculated a lower limit for $\mathrm{pH}$ at $7 \cdot 25$, base-excess $-8 \mathrm{~m}$-equiv/l (fully oxygen saturated) and an upper limit for $\mathrm{PCO}_{2}$ of $60 \mathrm{mmHg}$. These figures agree with 
my own observations of the acid-base status of healthy infants (Pearson, 1976). Values falling outside the lower 'limits' of normal are not necessarily associated with fetal depression (see below).

THE FALSE NEGATIVE pH

Occasionally the situation arises when a scalp pH value within the normal range has been recorded before delivery but, unexpectedly, the fetus is born in a depressed condition. This is the 'false negative' result, the frequency of which has been estimated by Beard (1970) to be in the order of 10 per cent of all scalp samples tested for clinical indications, and several factors may be operative.

The $\mathrm{pH}$ value of the scalp sample reflects the state of the infant at the time of sampling - a fact which limits its predictive value. Most samples are taken to assess the state of the fetus during the first stage of labour when a decision as to the most appropriate route of delivery may have to be made. During the second stage, if there is clinical evidence of fetal deterioration, delivery is usually expedited with forceps or ventouse. The second stage, of itself, results in a variable degree of fetal asphyxia (Wood et al, 1973; Pearson and Davies, 1974) and, therefore, unless delivery is imminent, poor overall correlation between the clinical state of the infant at birth and a scalp pH measured during the first stage can be expected (Khazin et al, 1969).

It is important that duplicate estimations of $\mathrm{pH}$ on a single sample agree with each other with an accuracy of $\pm 0.02 \mathrm{pH}$. If this modest level of agreement is not achieved, there is usually some methodological error and it is best not to accept the result.

Cord becomes entangled, especially around the fetal neck, in about 30 per cent of cephalic deliveries and causes fetal asphyxia.

The Apgar score at one minute can be depressed dramatically by the vigorous and overenthusiastic use of the mucus extractor, which, impinging upon the larynx, may provoke laryngeal spasm and fetal apnoea (Crawford, et al 1973).

Centrally acting drugs given to the mother cross the placenta and may result in the depression of a non-acidotic fetus. Pethidine promptly crosses the placental barrier and causes respiratory depression in the newborn and is associated with carbon dioxide retention by the neonate. This may persist for up to five hours after delivery in infants whose mothers have received only one dose of $100 \mathrm{mg}$ of pethidine (Koch and Wendel, 1968).

THE FALSE POSITIVE ph (INFUSION ACIDOSIS) Acid-base changes in the mother are reflected by the fetus, and significant correlations have been established between acid-base values obtained from fetal scalp blood and maternal blood. Furthermore, it is possible to influence acid-base values in the fetus by inducing changes in the mother. Goodlin and Kaiser (1957) used ammonium chloride and Rooth (1964) used sodium bicarbonate. Maternal lactic acidaemia induced by a hypertonic fructose (Laevulose) infusion in the mother was shown to cause a metabolic acidosis in the fetus by Pearson and Shuttleworth (1971), and Otey et al (1964) established a direct relationship with respect to lactate and pyruvate between maternal and fetal blood. The consensus of opinion at present supports the contention that acid metabolites pass freely to and fro across the placenta, probably in response to simple diffusion gradients.

In order to discriminate between fetal acidosis of asphyxial origin and that caused by maternal-fetal infusion, many workers have sought to compare maternal and fetal acid-base values. For instance, Beard et al (1967) used the concept of the $\Delta$ base deficit, the difference between the base deficit uncorrected for oxygen content in maternal peripheral venous blood and that of fetal scalp capillary blood. They found that the fetal base deficit was commonly lower than that of the mother and showed that a fetus with a low $\mathrm{pH}$ but a small difference between the maternal and fetal base deficit was more likely to have an acidosis derived from the mother than from intrauterine asphyxia. A more practical index, the $\Delta \mathrm{pH}$, was postulated by Rooth et al (1973) who suggested that fetal preacidosis be redefined as $\Delta \mathrm{pH} 0 \cdot 15-0.19$ and acidosis $\Delta \mathrm{pH} \geqslant 0 \cdot 20$ pH units. The comparisons made were between fetal scalp blood and antecubital vein blood taken without a tourniquet.

\section{Fetal Blood Sampling in Clinical Practice}

The two chief methods of monitoring the state of the fetus in utero are continuous electronic monitoring of fetal heart rate and intrauterine pressure (FHR/ UP) and fetal blood sampling.

Both methods have their disadvantages. If the FHR pattern is normal the probability of delivering an infant with a high Apgar score at five minutes is about 99 per cent. If ominous FHR patterns are present, the ability to predict correctly the degree of neonatal depression is low (Schifrin and Dame, 1972). The error lies in the prediction of lower five-minute Apgar scores than actually occur. However, it may be argued that the five-minute Apgar score reflects the efficiency of resuscitative procedures rather than the state of the fetus in utero.

Fetal blood sampling suffers from the disadvantage that it only measures the acid-base state of the fetus at the time of sampling. Many 'small-for-dates' 
infants become distressed early in labour during the latent phase. It often happens that the cervix is closed at this time and it requires considerable skill and not a little luck to obtain a good sample of fetal blood.

The two methods of monitoring, are, however, complementary and it is recommended that electronic FHR/UP monitoring should be provided for all patients in labour and that ominous FHR patterns or meconium staining should be checked by fetal blood sampling. In cases where the sample of fetal blood is 'borderline' and no correctable cause is found for fetal distress, then more discriminative information is provided by measuring the $\Delta \mathrm{pH}$. If the issue remains in doubt, and the unfavourable FHR patterns persist, the fetal blood sampling may be repeated within 30 minutes, or, sooner if the FHR patterns become more ominous.

Using this combined approach to intrapartum fetal surveillance it is now nearly three years since an infant died of intrapartum asphyxia at the University Hospital of Wales.

\section{References}

Adamsons, K., Beard, R. W., Cosmi, E. V., and Myers, R. E. (1968). The validity of capillary blood in the assessment of the acid-base state of the fetus. In Diagnosis and Treatment of Fetal Disorders, edited by K. Adamsons, p. 175. Springer, New York.

Adamsons, K., Jr., Behrman, R., Dawes, G. S., James, L. S., and Koford, C. (1964). Rescuscitation by positive pressure ventilation and tris-hydroxymethylaminomethane of rhesus monkeys asphyxiated at birth.J. Pediat., 65, 807-818.

Beard, R. W. (1970). Fetal blood sampling. Brit.J. hosp. Med., 3, 523-534.

Beard, R. W., and Morris, E. D. (1965). Foetal and maternal acid-base balance during normal labour. J. Obstet. Gynaec. Brit. Cwlth, 72, 496-506.

Beard, R. W., Morris, E. D., and Clayton, S. G. (1967). PH of foetal capillary blood as an indicator of the condition of the foetus. J. Obstet. Gynaec. Brit. Cwlth, 74, 812-822.

Crawford, J. S., Davies, P., and Pearson, J. F. (1973). Significance of the individual components of the Apgar score. Brit. J. Anaesth., 45, 148-158.

Dawes, G. S., Mott, J. C., Shelley, H. J., and Stafford, A. (1963). The prolongation of survival time in asphyxiated immature foetal lambs. J. Physiol. (Lond.), 168, 43-64.

Gare, D. J., Whetham, J. C. G., and Henry, J. D. (1967). The validity of scalp sampling. Amer. J. Obstet. Gynec., 99, 722-724.
Goodlin, R. C., and Kaiser, I. H. (1957). The effect of ammonium chloride induced maternal acidosis on the human fetus at term: 1. pH, hemoglobin, blood gases. Amer. J. med. Sci., 233, 662-674.

Hellegers, A. E., Armstead, E. E., Thomas, C. E., Burnett, A. M., Magovern, T. J., and Bruns, P. D. (1969). Effect of fetal metabolic acidosis upon oxygen environment. Amer. J. Obstet. Gynec., 105, 786-796.

Jacobson, L. (1970). Studies on acid-base and electrolyte components of human foetal and maternal blood during labour. Thesis, Student Litteratur, University of Lund.

Khazin, A. F., Hon, E. H., and Quilligan, E. J. (1969). Biochemical studies of the fetus. III. Fetal base and Apgar scores. Obstet. and Gynec., 34, 592-609.

Koch, G., and Wendel, H. (1968). The effect of Pethidine on the postnatal adjustment of respiration and acid-base balance. Acta obstet. gynec. scand., 47, 27-37.

Kubli, F. W. (1968). Influence of labor on fetal acid-base balance. Clin. obstet. gynec. scand., 11, 168-191.

Lumley, J., McKinnon, L., and Wood, C. (1971). Lack of agreement on normal values for fetal scalp blood. J. Obstet. Gynaec. Brit. Cwlth, 78, 13-21.

New York Academy of Science (1966). Report of ad hoc committee on acid-base terminology. Ann. N.Y. Acad. Sci., 133, 251-258.

Otey, E., Stenger, V., Eitzman, D., Gessner, I., and Prystowsky, H. (1964). Movements of lactate and pyruvate in the pregnant uterus of the human. Amer.J. Obstet. Gynec., 90, 747-752.

Pearson, J. F. (1976). Maternal and fetal acid-base balance. In The Fetus: Physiology and Medicine, Beard and Nathaniel. Saunders, London and Philadelphia. (To be published.)

Pearson, J. F., and Davies, P. (1974). The effect of continuous lumbar epidural analgesia upon fetal acid-base status during the second stage of labour. J. Obstet. Gynaec. Brit. Cwlth, 81, 975-979.

Pearson, J. F., and Shuttleworth, R. (1971). The metabolic effects of a hypertonic fructose infusion on the mother and fetus during labor. Amer. J. Obstet. Gynec., 111, 259-265.

Rooth, G. (1964). Early detection and prevention of foetal acidosis. Lancet, 1, 290-293.

Rooth, G., McBride, R., and Ivy, B. J. (1973). Fetal and maternal pH measurements. A basis for common normal values. Acta obstet. gynec. scand., 52, 47-50.

Saling, E. (1963). Die Blutgasverhältnisse und der SaüreBasen-Haushalt des Feten bei ungestörtem Geburtsablauf. Z. Geburtsh. Gynäk., 161, 262-292.

Saling, E. (1966). Aminoscopy and foetal blood sampling. Observations on foetal acidosis. Arch. Dis. Childh., 41, 472-476.

Schifrin, B. S., and Dame, L. (1972). Fetal heart rate patterns: prediction of Apgar score. J. Amer. med. Ass., 219, 13221325.

Wood, C., Ng, K. H., Hounslow, D., and Benning, H. (1973). The influence of differences of birth times upon fetal condition in normal deliveries. J. Obstet. Gynaec. Brit. Cwlth, 80, 289-294. 